\title{
Numerical Model for High Relative Capacity of Tensegrity Cable Domes
}

\author{
Logzit, N. $^{* *}$ and Kebiche, K. $^{2}$
}

\begin{abstract}
Tensegrity cable domes are types of structures composed of compressed bars and tensioned cables. They are characterised by an exceptional innovation in terms of lightness. Research in this area is flourishing, looking towards multiple applications. In the absence of an approach linking design to sizing, this article aims to propose a procedure to improve the design, while seeking to lighten the structure. The article uses the novelty of the methods, and in particular, the analysis of geometric non-linearity, to find the best solution, while checking the sizing criteria. Through a simple example of cable domes, we have shown the feasibility of this approach. The shape of the triangles of the design has a direct relationship to the relative capacity, and the study showed a considerable reduction in the weight of the structure. This method can easily be applied to other examples of more complex cable domes.
\end{abstract}

Keywords: Cable domes; tensegrity; relative capacity; sizing criteria.

\section{Introduction}

Cable domes are very light structures, consisting of struts and cables, and the overall shape creates a rounded form which results in a dome. Due to the existence of pin joints at the nodes, these structures are subject to mechanisms, which are stabilised by self-stress states. The principle of tensegrity creates a discontinuous compression sequence in the struts with a continuous tension in the cables. The most marked concept of these new systems is the David Geiger cable dome concept [1], which was designed in 1986 and was built in 1994 for the roof structure of the Georgia Dome (233.5 x $\left.186 \mathrm{~m}^{2}\right)$. Yuan et al. [2] have proposed several new forms of cable domes. Also, a general method referred to as double singular value decomposition (DSVD) [2], was proposed for the determination of various cable domes integral pre-stress.

In a study of cable dome optimisation, Kawaguchi et al. [3] showed that the optimal shape of the dome largely depends on the length of the outermost columns. Fu and Lan [4] and Fu [5] proposed several new types of cable domes with different geometric grids. The structural behaviour of the Georgia dome was then compared to that of their proposed domes.

\footnotetext{
${ }^{1}$ MAA, Civil Engineering Department, University of Biskra, Faculty of Sciences and Technology, Bordj Bou Arreridj University, Bordj Bou Arreridj (34.260), ALGERIA.

${ }^{2}$ Professor, LAM, Dept. of Civil Engineering, University of Sétif 1, ALGÉRIA

* Corresponding author; email: n_logzit@yahoo.fr
}

Note: Discussion is expected before July, $1^{\text {st }} 2020$, and will be published in the "Civil Engineering Dimension", volume 22, number 2, September 2020.

Received 31 January 2020; revised 05 May 2020; accepted 07 May 2020
Deng et al. [6] suggested the problem of shape finding of cable-strut assemblies could be reduced by using the iterative algorithm until equilibrium equations are satisfied. Special structural forms for cable domes were proposed by Regbielak [7]; however, the proposed forms do not fall into the category of cable domes, because rigid bars are connected in these forms. More recently, optimum self-stressing of domes with a single or with multiple integral selfstress modes is also examined by Yuan et al. [2]

The cable domes are structures with large spans that can reach hundreds of metres. It is possible to design cable domes capable of supporting 50 times their own weight. For conventional structures, this coefficient does not generally exceed the value of 10 , with a limited span.

Tensegrity structures are currently in full development and innovation. Recent research shows the interest accorded to these particular structures. A simple synthesis and classification of $2 \mathrm{D}$ tensegrity systems, with the concealment of the mechanisms, is presented by Paulina et al. [8]. Tensegrity structures have currently become an art form whose design principles are in many cases inspired by nature, and the performance of these structures is linked to design. Recent research has been presented in this sense by Jin and Kanggeun [9]. Polinceusz [10] offers the automatic possibility to use a computer to analyze the shape of tensegrity structures applied to the covering of architectural space.

It is in this context that cable domes are presented as one of the innovative and efficient solutions for shapes, architecture and use of space. 
The purpose of this article is to improve the relative capacity of cable domes. The desired result is to have the highest relative capacity coefficient by checking the sizing criteria. Subsequently, the influence of the shape parameters on the relative capacity coefficient will be studied.

\section{Relative Capacity Coefficient and Verifi- cation of Optimisation Criteria}

With identical spans and shapes, experience shows that traditional concrete structures can support a vertical load of about twice their own weight and sometimes more. Steel structures can support more than 10 times their own weight. The cable domes of tensegrity sometimes exceed a coefficient of the order of
50, which characterises them as very light structures. The relative capacity coefficient $\left(\mathrm{C}_{\mathrm{cr}}\right)$ of a cable dome is the ratio of the total vertical load supported by this structure to its self-weight. In this study, an approach for improving relative capacity is proposed. For this reason, an iterative verification of the sizing criteria is made. These criteria are the shape criterion, the overall stability criterion, and the criterion of resistance and elements' stability.

To validate the reliability of this model, a numerical simulation was carried out in this paper. A certain cable dome should be defined to serve as the basic structure for the verification procedure (Figures 1 and 2 ). The study will begin with a cable dome with a diameter of $\mathrm{D}=21 \mathrm{~m}$ (Figures 3 and 4, Table 1).

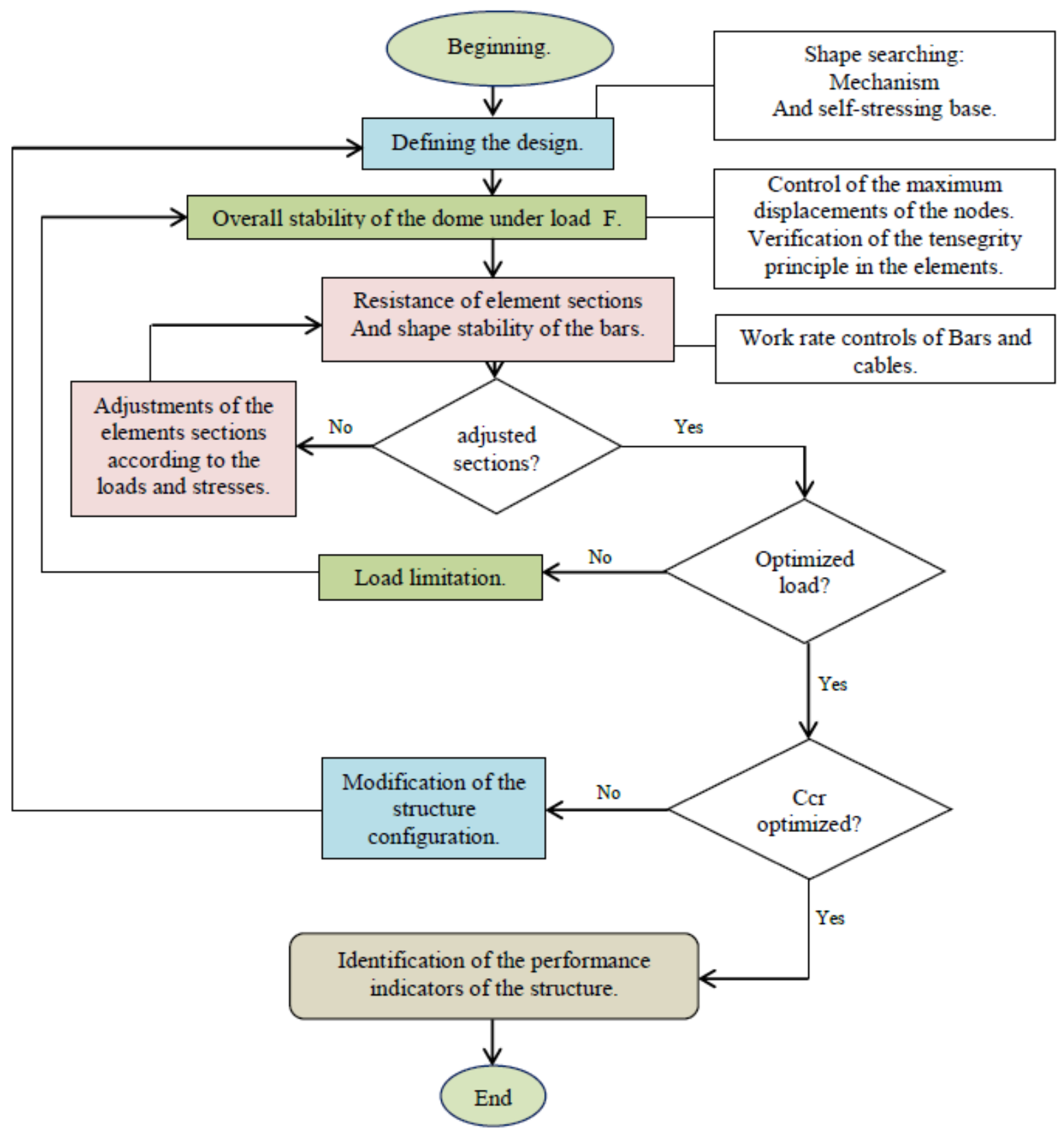

Figure 1. General Algorithm for the Optimisation of Cable Domes Design 


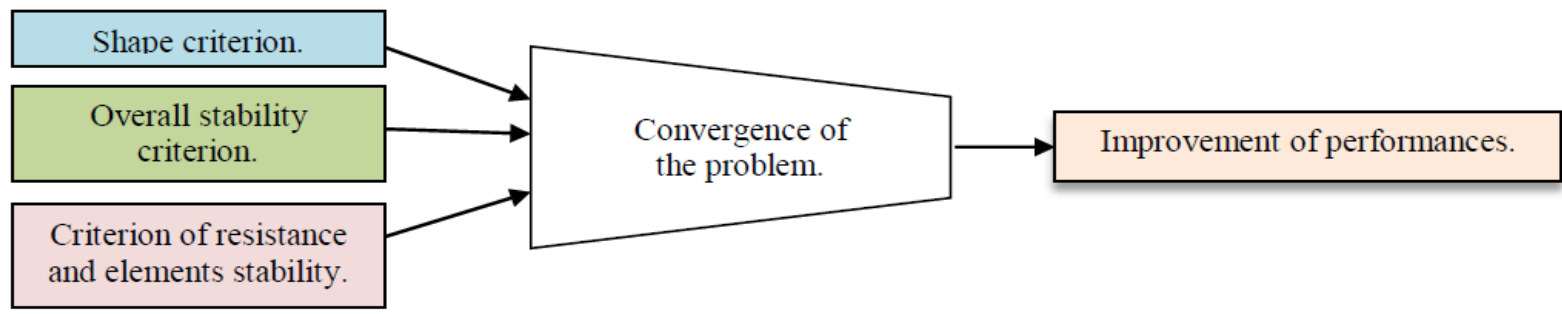

Figure 2. General Scheme for Optimisation Criteria Verification of Cable Domes Design

To take into consideration all the parameters of mechanical behaviour present in this study which affect the optimisation of the domes' design, and to automate this process of verification, it is proposed to follow the approach described in the form of an algorithm (Figure 1), based on the verification of the design criteria.

The initial structure of the dome will be subject to a process of a behavioural study and by checking the criteria of optimisation to be able to have the corrections and possible potential adjustments to the improvement of the structure performances.

This process is mainly based on a repetitive approach which includes the convergence of three optimisation criteria groups of cable domes towards a single performance improvement path (Figure 2).

Overall stability, resistance and the stability of all elements subject to normal forces are verified according to the provisions and limits described following Eurocode 3 [11]. The deflection at the centre of the dome is limited at $\mathrm{D} / 250$, in which $\mathrm{D}$ is the diameter of the dome. The optimisation of the design of the cable dome structure is characterised by the performance index termed the "coefficient of relative capacity".

\section{Methods of Study and Means of Analysis}

The design of the dome used in this study involves the first stage called shape research. Where the authors define the geometry of the system that allows the setting up of a self-stressing. For that, the authors use the method developed by Vassart et al. [12], whose work is based on the research done by Pellegrino and Calladine [13].

The $\mathrm{N}$ equilibrium equations of a reticulated system or a cable dome, which transcribe the equilibrium of the nodes under the effect of external forces and normal forces, lead to a system of linear equations which can be represented in the following matrix form:

[A] $\{\mathrm{q}\}=\{\mathrm{f}\}$

[A] is the equilibrium matrix ( $\mathrm{N}$ rows and b columns), $\{\mathrm{q}\}$ is the vector with b components of the force density coefficients of the elements, \{f\} is the vector with $\mathrm{N}$ components of the external forces applied to the nodes.

The transformation of the system of linear equations into matrices, and the resolution of the problem, were illustrated by Pellegrino and Calladine [13] on a simple example of a bar with two joints.

For cable domes, a reticulated system will have at least one state of self-stress, if there is at least one non-zero force density coefficient vector compatible with the static equilibrium of the system in the absence of external forces. The mechanisms of the system are determined mathematically based on the possibility of at least one non-zero displacement vector of nodes which does not involve any variation of the first order, in the length of the system elements. As for the verification of self-stress states in the elements of cable domes, one can use the method based on the direct equilibrium of the nodes proposed by Cao and Zhang [14].

Concerning the study of mechanical behaviour, the authors use a model of analysis proposed by Kebiche et al. [15] and by Ben Kahla and Kebiche [16], based on the model proposed by Bathe et al. [17]. This procedure was applied to study the mechanical behaviour of tensegrity systems in the assumption of large displacements. See also the work of Murakami [18]. Fu [5] studied the mechanical behaviour of cable domes through a comparison between proposed structural systems and that of the Georgia dome.

The behavioural study approach uses the finite element method in the assumption of non-linear geometrics, based on an incremental writing of the virtual works principle according to the total Lagrangian formula. It leads to the development of a nonlinear equations system, which highlights the tangent stiffness matrix and the internal stress vector.

The resulting expression represents a non-linear equation system, and the resolution method used for this type of problem is that of Newton-Raphson. The authors will have to consider several equilibrium states each corresponding to a loading step. For each of these steps, an iterative resolution by variable correction will be used to converge the system towards a state of equilibrium. The equilibrium is satisfied when the residue becomes negligible. 


\section{Numerical Application}

To validate the proposed procedure, a tensegrity cable dome has been designed, which will be studied to verify the sizing criteria.

The dome studied in this paper has a diameter of 21 $\mathrm{m}$ and the typology of the structure will be changed according to the desired performance. The dome consists of 26 nodes and 57 elements, 9 of which are metal tube bars and the rest are cables. Figures 3 and 4, and Table 1, present the geometric and mechanical data of the basic initial typology of the studied dome.

Behaviour of the Dome under Load F: The chosen study procedure consists of blocking the represented section at the eight nodes: $1,2,3,4,5,6$, 7 and 8 (the nodes are blocked in three directions), and soliciting the represented section via the nodes: from 9 up to 17 by a force $\mathrm{F}$ concentrated on these nodes and directed downwards.

During the loading along the Y-axis of the bars from 50 up to 57, in the direction of gravity, Figure 5 illustrates that the behaviour of the module is linear, nonlinearity is not noted here, because of the relative stiffness of the structure and the high level of selfstress. The displacement of the nodes increases proportionally as the external load increases.

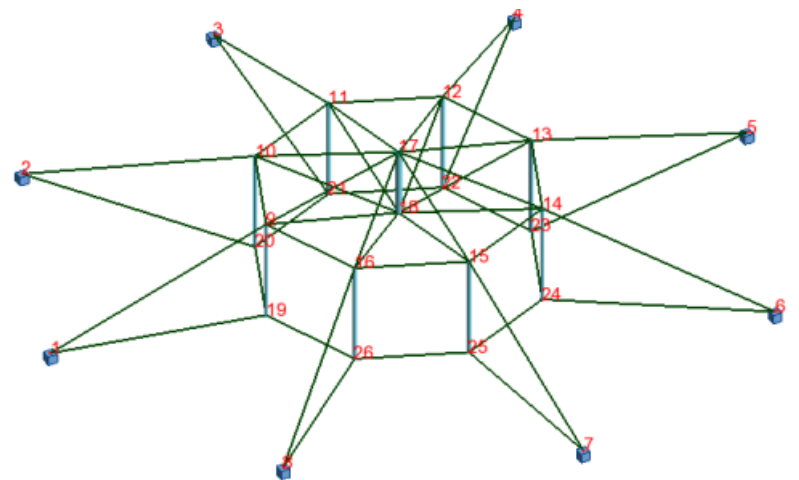

(a) Perspective view

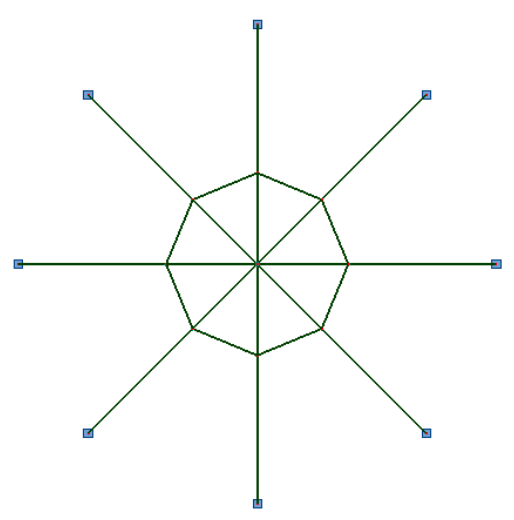

(b) Plan view

Figure 3. General View of the Dome

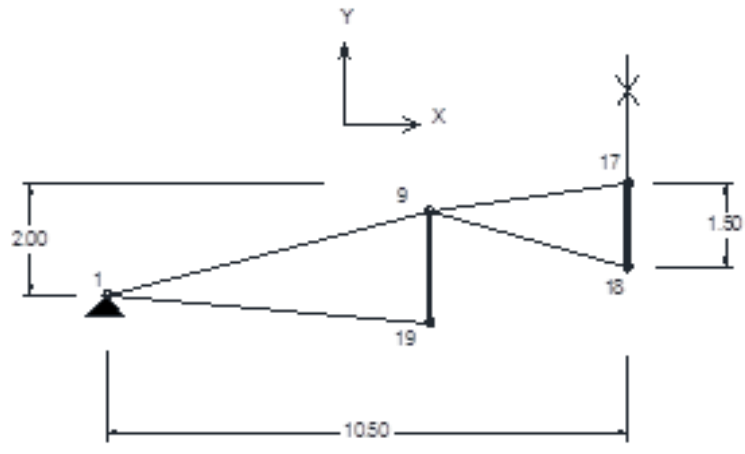

(a) Perspective view

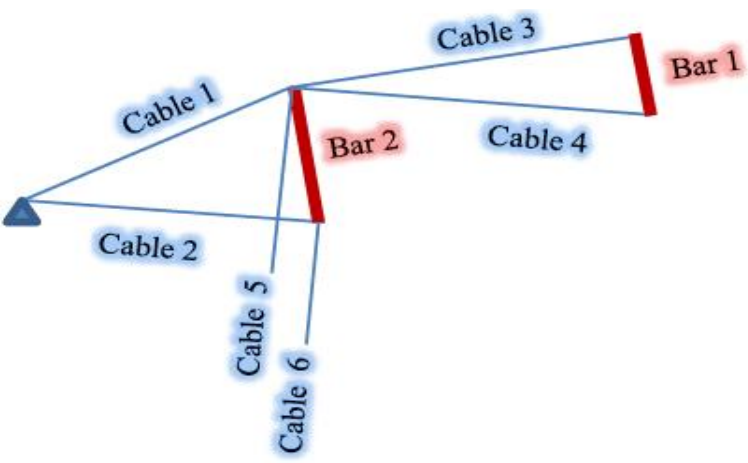

(b) Section view

Figure 4. Diametrical Cut

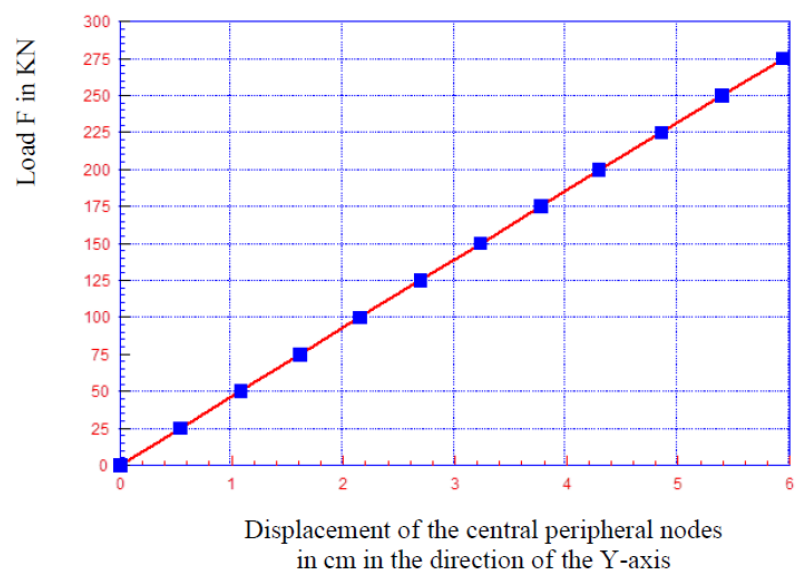

Figure 5. Behaviour of the Dome Structure Subject to Load F

Verification of the tensegrity principle (forces in the most sensitive cables): With regard to the evolution of the tension in the most sensitive cables, Figure 6 shows linear behaviour for all these cables. These upper cables are loosened as the load F increases to a value close to $\mathrm{F}=260 \mathrm{KN}$, after this threshold, these cables lose their stiffness and they loosen (limit of validation of the design). The other cables (not shown here) show linear behaviour and remain stressed by traction in this loading range.

Control of the Cables Working Rates: The behaviour of the cables (Figure 7) is almost linear, the working rate of cables, expressing the ratio of the applied stress on the limit stress of the cables, 
Table 1. The Elements Geometric and Mechanical Characteristics.

\begin{tabular}{|c|c|c|c|c|c|}
\hline Element's name & $\begin{array}{c}\text { List of cables and } \\
\text { bars }\end{array}$ & Section AX $\left[\mathrm{cm}^{2}\right]$ & $\begin{array}{c}\text { Young's module } \\
{\left[\mathrm{KN} / \mathrm{cm}^{2}\right]}\end{array}$ & $\begin{array}{c}\text { Limit constraint } \\
{\left[\mathrm{KN} / \mathrm{cm}^{2}\right]}\end{array}$ & Self-stress base \\
\hline Cable_1 & 1 to 8 & 16,50 & \multirow{6}{*}{16000} & \multirow{6}{*}{87.44} & 0.784 \\
\hline Cable_2 & 9 to 16 & 20,90 & & & 0.784 \\
\hline Cable_3 & 17 to 24 & 10,60 & & & 0.359 \\
\hline Cable_4 & 25 to 32 & 2.81 & & & 0.184 \\
\hline Cable_5 & 33 to 40 & 4,30 & & & 0.299 \\
\hline Cable_6 & 41 to 48 & 24.90 & & & 1.000 \\
\hline Bar_1 & 49 & 40,75 & \multirow{2}{*}{21000} & \multirow{2}{*}{35.50} & 0.357 \\
\hline Bar_2 & 50 to 57 & 26,72 & & & 0.176 \\
\hline
\end{tabular}

increases with the load $\mathrm{F}$ for the three cable families; 9 to 16 (Cable_2), 17 to 24 (Cable_3), and 41 to 48 (Cable_6), in contrast, the rest of the cable families; 1 to 8 (Cable 1), 25 to 32 (Cable 4), 35 to 40 (Cable4) the working rate decreases with the increase in the load F.

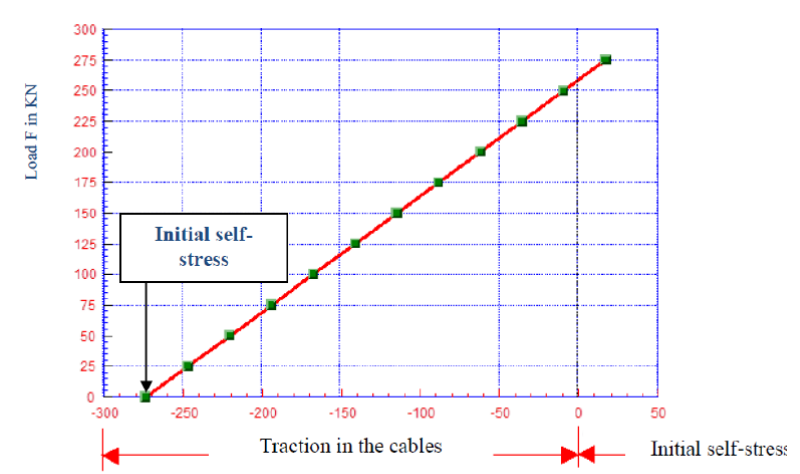

Forces in the cables $25,26,27,28,29,30,31$ and 32 in $\mathrm{KN}$

Figure 6. Forces in the Highly Sensitive Cables

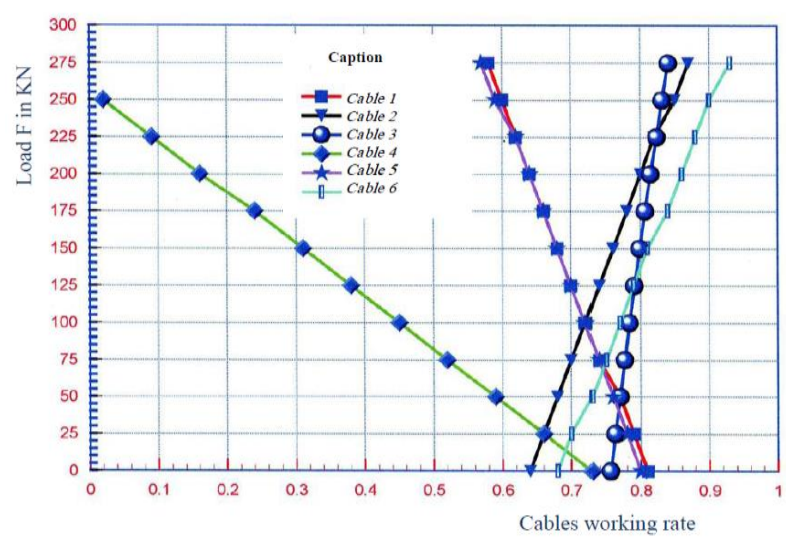

Figure 7. Working Rate of the Cables

All cable families have a work rate situated between 0.57 and 0.93 in the loading range, except for one cable family of 25 to 32 (Cable_4) where the lower limit converges towards zero, which implies a reconciliation of the threshold of stress in compression.

Control of Resistance and Stability at the Buckling of the Bars: The central bars display linear behaviour (Figure 8). The compression in the bar increases, the working rate of the central bar is greater than that of the peripheral bars, this is justified by the distribution of the self-stress at the level of the bars. For all load F values, the working rate of the bars for the resistance and the buckling stability is in the range: 0.28 and 0.84 .

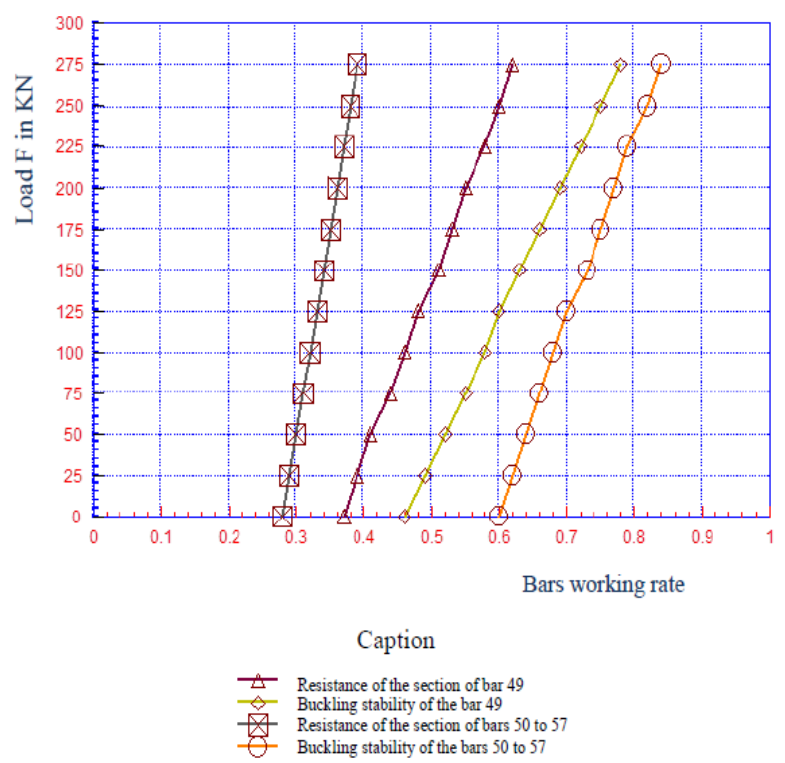

Figure 8. Working Rate of the Bars

\section{Structure Analysis}

Coefficient of Relative Capacity of the Structure: This structure has a linear mechanical behaviour in all the studied parameters; its weakness remains always located at the central part where the cables are loosened at a loading threshold of $\mathrm{F}=260$ $\mathrm{KN}$. The relative capacity coefficient of this structure is $\mathrm{Ccr}=74$.

Proposal of New Configurations of the Dome Structure: It has been observed through the mechanical behaviour of the studied dome that the overall instability of the structure is first and foremost related to the central part of the dome, where the most sensitive cables are loosened at first and at the surface of the triangles constituting the tensegrity principle of the dome. The authors have also found that the load limit for the dome structure was deduced from the critical load value just before the loosening of the most 
sensitive cables. Thus, the improvement of the relative capacity of the structure automatically goes through a modification of the design to remedy this point of weakness.

To achieve a better design, one must operate on the criteria proposed in this work to attain an improved configuration of the initial structure. The bottom line is to find a configuration with a significant improvement across all performance criteria. The predominant parameters of cable domes design are the basic shape of the peripheral triangles constituting the principle of tensegrity in the dome, the deflection in the centre of the dome, and finally, the length of the central bar. The reference structure of the studied dome will then be modified by operating on these parameters.

Based on this principle of changing the reference structure configuration (Figure 9), several structures were studied, we propose the results of two structures (Figures 10 and 11).

These two structures labelled 2 and 3 have been subjected to the same verification process of the selected criteria, and the final result yielded the structural performance of the studied domes with relative capacity coefficients of 77 and 82 , respectively. We noted a clear improvement.

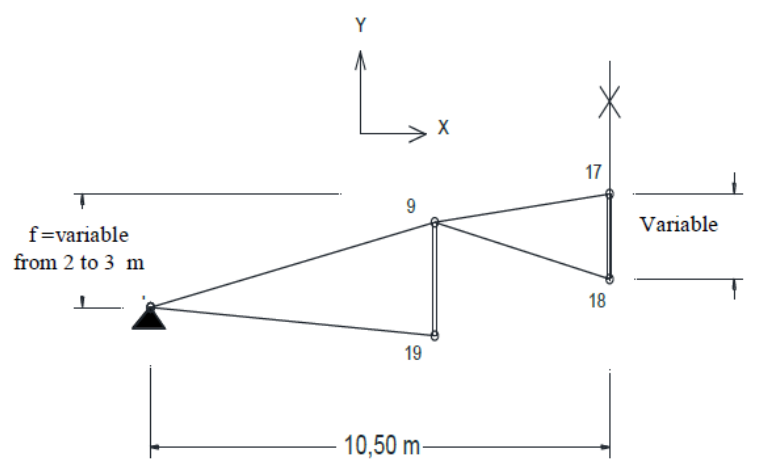

Figure 9. Semi Diametrical Cut of the Dome Cables: Change of the Structures' Configuration.

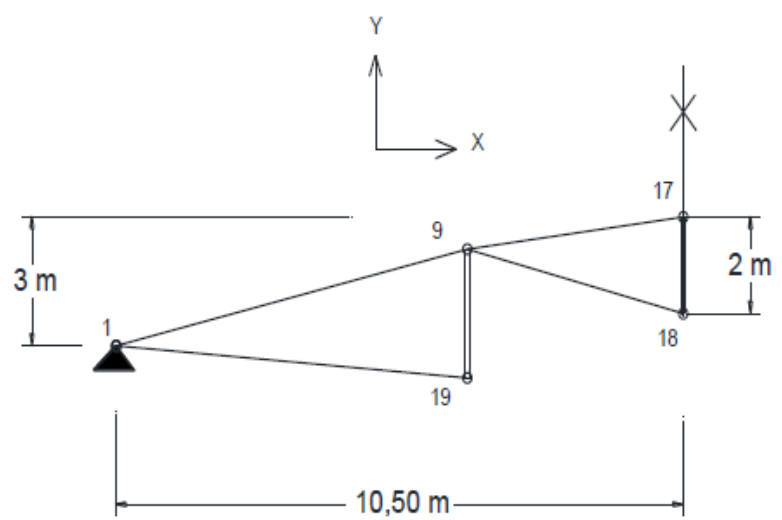

Figure 10. Semi Diametrical Cut of the Cable Dome. Structure 2

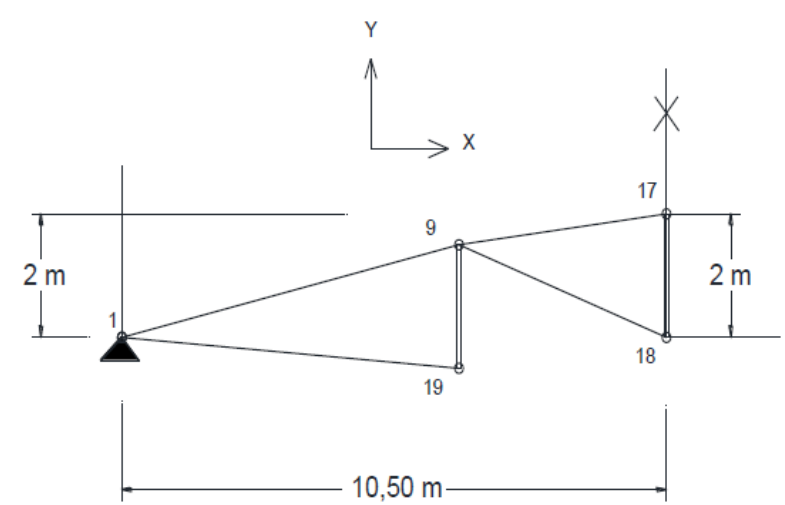

Figure 11. Semi Diametrical Cut of the Cable Dome. Structure 3

\section{Summary of Study Results and Discussion}

At the end; all the criteria proposed in this study lead to the main parameters that can govern an optimal design of the cable domes, so the authors summarise the results as follows (Table 2).

To find a high-performance structure with a high coefficient of relative capacity, it is clear via this numerical simulation that the design of the cable dome must have the highest possible ratio $\left(\mathrm{St} / \mathrm{S}_{\mathrm{D}}\right)$.

Where:

$\mathrm{S}_{\mathrm{t}}$ : Is the area in $\mathrm{m}^{2}$ of the triangles of the dome in a meridian direction,

Sp: Is the area in $\mathrm{m}^{2}$ of the dome.

At least for the typical structures of tensegrity-based cable domes, the objects of the present study consisted of the following elements:

$\checkmark$ Fixed supports on the periphery of the dome

$\checkmark$ Peripheral arrangement of tensegrity triangles in a meridian direction

$\checkmark$ Peripheral cables in a circumferential direction

$\checkmark$ The central part of the dome.

Having a ratio of the deflection $\mathrm{f}$ of the dome to its diameter $\mathrm{D}$ of $\mathrm{f} / \mathrm{D}=0.095$ to 0.143 , we suggest a coefficient of design optimisation (Figure 12) of a constant value equal to $\mathrm{COC}_{\mathrm{OC}}=1050$.

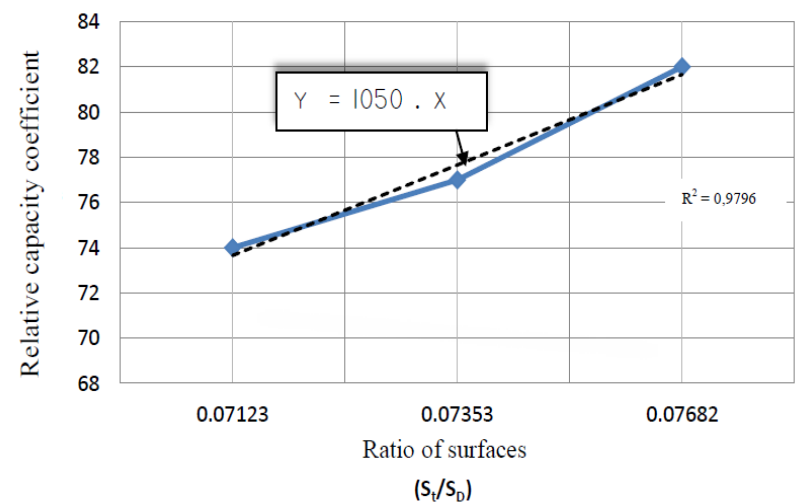

Figure 12. Optimisation of the Dome Cable Design 
Table 2. Main Parameters for Optimising the Cable Domes Design

\begin{tabular}{ccccccc}
\hline $\begin{array}{c}\text { Structure } \\
\text { of the cable dome } \\
\text { which fulfil } \\
\text { the principle of } \\
\text { tensegrity. }\end{array}$ & $\begin{array}{c}\text { Ratio of the } \\
\text { dome's } \\
\text { deflection on its } \\
\text { diameter } \\
\mathbf{f} / \mathbf{D}\end{array}$ & $\begin{array}{c}\text { Surface of } \\
\text { triangles in a } \\
\text { meridian } \\
\text { direction } \\
\mathbf{S t}\left(\mathrm{m}^{2}\right)\end{array}$ & $\begin{array}{c}\text { Dome } \\
\text { Cable } \\
\text { Surface } \\
\mathbf{S}_{\mathbf{D}} \\
\left(\mathrm{m}^{2}\right)\end{array}$ & $\begin{array}{c}\text { Ratio of } \\
\text { surfaces } \\
\left(\mathrm{St} / S_{D}\right)\end{array}$ & $\begin{array}{c}\text { Design } \\
\text { Relative capacity } \\
\text { Coefficient } \\
\mathbf{C}_{\mathbf{c r}}\end{array}$ & $\begin{array}{c}\text { optimisation } \\
\text { coefficient } \\
\text { Ccr }\end{array}$ \\
$\begin{array}{c}\text { Structure 1 } \\
\text { Structure 2 }\end{array}$ & 0.095 & 25.5 & 358 & 0.07123 & 74 & $\mathbf{1 0 3 9}$ \\
Structure 3 & 0.143 & 27.5 & 374 & 0.07353 & 77 & $\mathbf{1 0 4 7}$ \\
\hline
\end{tabular}

Through this coefficient, we can directly estimate the relative capacity of a dome structure by knowing the initial parameters of form, and we can write:

$\mathrm{C}_{\mathrm{cr}}=1050 \times\left(\mathrm{S}_{\mathrm{t}} / \mathrm{S}_{\mathrm{D}}\right)$

Where:

$\mathrm{C}_{\text {cr: }}$ Is the coefficient of the relative capacity of the dome,

1050: Is the coefficient of optimisation of the design (Coc).

The weight of the current dome structure proposed in this article is only $9.27 \mathrm{Kg} / \mathrm{m}^{2}$. As an example, the weight of a tensegrity structure (bidirectional flat double-layer system of the Laboratory of Mechanics and Civil Engineering, Montpellier 2, France, built in $2000)$ is $11 \mathrm{~kg} / \mathrm{m}^{2}$ [19].

Thanks to the numerical simulation of this study, it is found that the shape of the dome considerably influences the optimisation of the design. The conclusion of Motro [20] on tensegrity structures: coupling between form, forces and their structural morphology, is therefore confirmed here.

\section{Conclusion}

The procedure proposed in this paper has yielded satisfactory results. Through the iterative verification of the sizing criteria, the mechanical performance of the cable dome's structure has been significantly improved.

Through the optimisation of the dome design studied by the proposed model, an improvement in performance of around $10 \%$ is recorded.

A numerical formula in this regard has been proposed for the direct determination of the relative capacity coefficient of a cable dome structure, from data relating to its shape. This procedure can easily be envisaged for more complex cable dome sizes.

\section{References}

1. Tibert, G., Numerical Analyses of Cable Roof Structures, Licentiate Thesis, Department of
Structural Engineering Royal, Institute of Technology, Stockholm, Sweden, TRITA-BKN, 1999, Bulletin 46.

2. Yuan, X., Chen, L., and Dong, S., Prestress Design of Cable Domes with New Forms, International Journal of Solids and Structures, 44(9), 2007, pp. 2773-2782.

3. Kawaguchi, M., Tatemichi, B., Ikuo, and Chen P.S., Optimum Shapes of a Cable Dome Structure, Engineering Structures, 21(8), 1999, pp. 719-725.

4. Fu, F. and Lan T.T., A Study of Tensegrity Cable Domes, Space Structures, Thomas Telford, London, 5(1), 2002, pp. 21-30.

5. Fu F., Structural Behaviour and Design Methods of Tensegrity Domes, Journal of Constructional Steel Research, 61(1), 2005, pp. 23-35.

6. Deng, H., Jiang, Q.F., and Kwan, A.S.K., Shape Finding of Incomplete Cable-Strut Assemblies Containing Slack and Prestressed Elements, Computers and Structures, 83(21-22), 2005, pp. 1767-1779.

7. Regbielak J., Special Forms of Structural Systems Proposed for Cable Domes, Advances in Architecture Series, Mobile and Rapidly Assembled Structures, 3(3), 2000, pp. 93-99.

8. Paulina O., Joanna K., and Wojciech G., Truth and Myths about 2D Tensegrity Trusses, Applied Sciences, 9, 2019, p. 179.

9. Jin K. and Kanggeun P., The Design Characteristics of Nature-inspired Buildings, Civil Engineering and Architecture, 6(2), 2018, pp. 88107.

10. Polinceusz, P., Structure of Architecture Tensegrities in the Construction of Architectural Space, Architecture Civil Engineering Environment, 1(2019), 2019, pp. 45-52.

11. EN 1993-1-1, Eurocode 3: Design of steel structures-part 1-1: General rules and rules for buildings, CEN, Brussels, 2014.

12. Vassart, N., Laport, R., and Motro, R., Determination of Mechanisms' Order for Kinematically and Statically Undetermined Systems, International Journal of Solids and Structures, 37(28), 2000, pp. 3807-3839. 
13. Pellegrino, S. and Calladine C.R., Matrix Analysis of Statically and Kinematically Inseminate Frameworks, International Journal of Solids and Structures, 22(4), 1986, pp. 409-428.

14. Cao, Q. and Zhang, Z., A Simplified Strategy for Force Finding Analysis of Suspendomes, Engineering Structures, 32(1), 2010, pp. 306-318.

15. Kebiche, K., KaziAoual, M.N., and Motro, R., Geometrical Nonlinear Analysis of Tensegrity Systems, Engineering Structures, 21(9), 1999, pp. 864-876.

16. Kahla, N.B. and Kebiche, K., Nonlinear Elastoplastic Analysis of Tensegrity Systems, Engineering Structures, 22(11), 2000, pp. 1552-1566.
17. Bathe, K.J., Ramm, E., and Wilson, E., Finite Element Formulations for Large Deformation Dynamic Analysis, International Journal for Numerical Methods in Engineering.

18. Murakami, H., Static and Dynamic Analyses of Tensegrity Structures, Part 1: Nonlinear Equations of Motion, International Journal of Solids and Structures, 38(20), 2001, pp. 3599-3613.

19. Gómez-Jáuregui, V., Tensegrity Structures and their Application to Architecture. Msc Dissertation, School of Architecture, Queen's University Belfast, 2004, $239 \mathrm{p}$.

20. Motro, R., Structural morphology of tensegrity systems, Asian Journal of Civil Engineering (Building and Housing), 10(01), 2009, pp. 1-19. 